\title{
Reversible and Irreversible Adsorption of Surfactants at a Hanging Mercury Drop Electrode
}

\author{
Hiromiti Sawamoto \\ Faculty of Education, Kochi University, Akebono-cho, Kochi 780-8520, Japan
}

\begin{abstract}
The adsorption-desorption phenomena of surfactants were studied by measuring differential capacity-potential curves in a static solution and differential capacity-time curves in a flowing solution. The surfactants investigated were Aerosol OT, cetylpyridinium chloride, Hyamin 1622, tetrabutylammonium bromide, Triton X-100 and trioctylphosphineoxide. The differential capacity-potential and differential capacity-time curves for these surfactants showed different shapes, with and without peaks. The differential capacity-time curves were used to study the adsorption reversibility of the surfactants at a mercury electrode. The adsorptions of Hyamin 1622 and Triton X-100 were irreversible at all the potentials investigated. The adsorptions of Aerosol OT and trioctylphosphineoxide were irreversible except at the potential more positive than $-0.2 \mathrm{~V}$. The adsorption of tetrabutylammonium bromide was almost reversible at any potential investigated. The adsorption of cetylpyridinium chlolide was complicated, indicating different orientations of adsorption.
\end{abstract}

(Received March 10, 2003; Accepted July 31, 2003)

\section{Introduction}

As a large amount of surfactants is produced and used every year, it is important to study the analysis of surfactants. ${ }^{1}$ Electrochemical analysis of surfactants was reviewed, ${ }^{2}$ in this review tensammetric methods to measure the differential capacity-potential curves were described. An indirect tensammetric method for the determination of non-ionic surfactants was reported. ${ }^{3}$ An indirect tensammetric method and adsorptive stripping tensammetry for the determination of the concentration of the surfactant were also investigated. ${ }^{4}$ To develop an analytical method to determine surfactants by using adsorption phenomena, it is necessary to study the adsorption phenomena of surfactants. The adsorption behavior of a mixture of sodium dodecyl sulfate and dodecyl alcohol was studied on a mercury electrode on the basis of capacity measurements. ${ }^{5}$ Adsorption at the mercury electrode in relation to micelle and mixed micelle formation was studied. ${ }^{6}$

Many studies of the adsorption of organic compounds on mercury electrodes have been reported and thermodynamic methods of adsorption data of organic compounds were described. $^{7} \quad$ In these studies, usually the differential capacity-potential curves have been measured to investigate the adsorption phenomena of organic compounds. Recently, Rueda et al. ${ }^{8}$ reported condensed film formation detected from differential capacity data at high hypoxanthine concentrations. Pospisil et al. ${ }^{9}$ studied the adsorption of both $\alpha$ - and $\gamma$-cyclodextrins on the mercury electrode by measuring double layer capacity. Stauffer et al. ${ }^{10}$ studied the various physical forms of dioleoyl phosphatidylcholine onto a $\mathrm{Hg}$ electrode. Damaskin et al. ${ }^{11}$ studied about coadsorption of ions and organic molecules. They proposed a three parallel capacitor model to interpret the results.

It was found that adsorption-desorption phenomena can be studied by measuring differential capacity-time curves with a flow injection method. ${ }^{12}$ When the adsorption-desorption phenomena of alcohols were studied by this method, it was found that the adsorption of methanol was irreversible and those of 1-pentanol and 1-octanol were reversible. ${ }^{13}$ Reversible adsorption of 1-octanol on the adsorbed layer of methanol was also observed. ${ }^{14}$ Adsorption of nitriles, ${ }^{15}$ pyridine, ${ }^{16}$ quinoline ${ }^{17}$ and ketones ${ }^{18}$ has been studied by this method. In this research similar studies are performed for surfactants.

\section{Experimental}

The experimental equipment used was almost the same as that described previously. ${ }^{12}$ The supporting electrolyte solution ( $\left.0.05 \mathrm{M} \mathrm{Na}_{2} \mathrm{SO}_{4}\right)$ from which oxygen was removed by passing nitrogen was flowed by a peristaltic pump. Several materials: $0.01 \%$ Aersol OT (di-iso-octyl sodium sulfosuccinate), $10 \mathrm{mM}$ cetyl pyridium chloride, $0.01 \%$ Hyamin 1622 (diisobutylphenoxyethoxydimethyl-benzeylammonium chloride), 1 $\mathrm{mM}$ tetrabutylammonium bromide, saturated solution of Triton X-100 (polyoxyethylene(10)octylphenyl ether) and saturated solution of trioctylphosphine oxide were injected through a bulb. Aersol OT, cetyl pyridium chloride, tetrabutylammonium bromide and Triton X-100 were purchased from Wako (Osaka). Hyamin 1622 and trioctylphosphine oxide were purchased from Nacalai (Kyoto). An active charcoal column was connected before the bulb to remove trace impurities in the supporting electrolyte solution. The electric detection cell was made with a teflon tube which is similar to one that was described elsewhere; ${ }^{12}$ differential capacity was measured with a phase sensitive a.c. polarograph (Fuso Models 311B and 332B). An alternating voltage with a frequency of $50 \mathrm{~Hz}$ and an amplitude of $5 \mathrm{mVpp}$ was used. The hanging mercury drop electrode used was a Metrohm EA290; its area was $1.40 \times 10^{-2} \mathrm{~cm}^{2}$. 


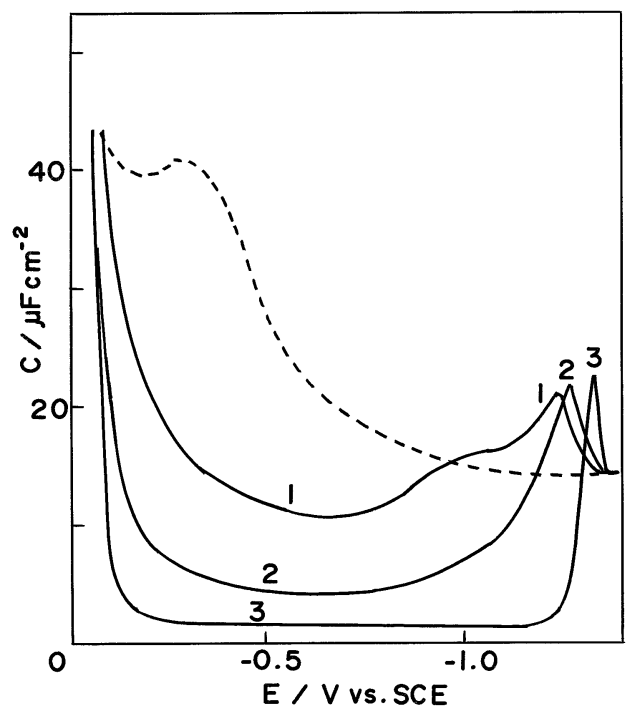

Fig. 1 Differential capacity-potential curves for Aerosol OT at a mercury electrode in $0.05 \mathrm{M} \mathrm{Na}_{2} \mathrm{SO}_{4}$. Concentration of Aerosol (weight \%): (1) 0.002; (2) 0.004; (3) 0.01; (----) $0.05 \mathrm{M} \mathrm{Na}_{2} \mathrm{SO}_{4}$ alone.

\section{Results and Discussion}

The differential capacity-potential curves for Aerosol OT at a mercury drop electrode in the static solutions are shown in Fig. 1. The peaks around $-1.2 \mathrm{~V}$ could be observed at the concentrations of Aerosol OT higher than $0.0006 \%$. As the concentration of Aerosol OT increased, the peak potential was shifted to the negative potential. Therefore the peaks are due to the adsorption-desorption of Aerosol OT. As Aerosol OT is an anionic surfactant, it is desorbed at a more negative potential than the peak potentials.

The effects of adsorption potential on differential capacity-time curves by the flow injection method for Aerosol OT are shown in Fig. 2. Although the differential capacity-potential curves are shown up to $260 \mathrm{~s}$, the experiments were done up to $500 \mathrm{~s}$ for all the compounds investigated in this paper. Aerosol OT was adsorbed reversibly at $-0.05 \mathrm{~V}$. A part of the adsorbed molecules was desorbed at $-0.1 \mathrm{~V}$. The adsorption of Aerosol OT was irreversible in the potential region between $-0.2 \mathrm{~V}$ and $-0.9 \mathrm{~V}$. A part of the adsorbed Aerosol OT was desorbed at $-1.0 \mathrm{~V}$. No adsorption was observed at $-1.2 \mathrm{~V}$. Similar studies were performed about two anionic surfactants: sodium dodecyl sulfate and sodium dodecylbenzenesulfonate. ${ }^{19}$ Adsorption of sodium dodecyl sulfate at the potential more positive than $-0.2 \mathrm{~V}$ was irreversible, while that at the potential more negative than -0.4 $\mathrm{V}$ was reversible. Adsorption of sodium dodecylbenzenesulfonate was irreversible at the potential more positive than $-0.8 \mathrm{~V}$. It was reversible at the potential more negative than $-1.0 \mathrm{~V} .19$

Reversible and irreversible adsorption can be judged by the differential capacity-time curves. When the introduced organic molecules reach the electrode to be adsorbed, differential capacity decreases. After a certain time, only supporting electrolyte solution is carried to the electrode. If the adsorption is reversible, adsorbed molecules are desorbed from the electrode, leading to the increase in the differential capacity.

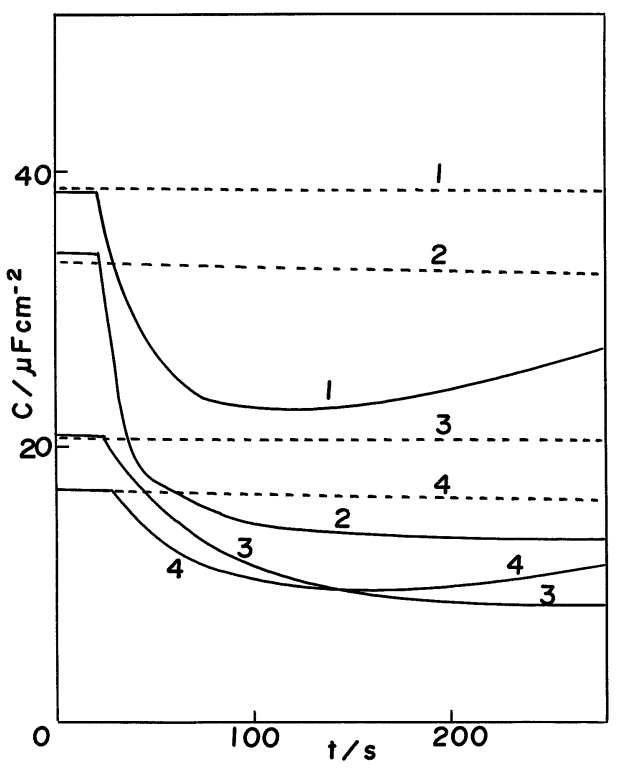

Fig. 2 Effect of adsorption potential on differential capacity-time curves for Aerosol OT. Injected solution: $5 \mu \mathrm{L}$ of $0.01 \%$ Aerosol OT. Adsorption potential (V vs. SCE): (1) -0.1 ; (2) -0.3 ; (3) -0.6 ; (4) -1.0. Dashed lines: without injection.

Although the desorption speed was very slow, the adsorption of Aerosol OT at $-0.1 \mathrm{~V}$ and at $-1.0 \mathrm{~V}$ are considered to be reversible, while the adsorptions at $-0.3 \mathrm{~V}$ and at $-0.6 \mathrm{~V}$ are irreversible.

Adsorption of organic compounds on an electrode is considered to be a replacement reaction with water molecules at the electrode. ${ }^{20}$ In order to consider the replacement reaction, we must know the structure of water at the electrode. Recently water structures at the electrode have been discussed..$^{21-25}$

It is considered that reversible adsorption involves the replacement of the water molecules at the secondary water layer by the organic compounds and that irreversible adsorption involves the replacement of the water molecules at the primary water layer by the organic compounds. ${ }^{13,14}$

Adsorption of anionic surfactants was almost reversible at any potential more positive than $-0.1 \mathrm{~V}$. At $-0.2 \mathrm{~V}$, the adsorption of all anionic surfactants investigated became irreversible. The adsorption of sodium dodecyl sulfate was irreversible at any potential between $-0.2 \mathrm{~V}$ and $-0.3 \mathrm{~V}$. Half of the adsorbed sodium dodecyl sulfate was desorbed at $-0.4 \mathrm{~V}$. It was reversible at the potential more negative than $-0.6 \mathrm{~V} .{ }^{19}$ The adsorption of sodium dodecylbenzenesulfonate was irreversible at the potentials between $-0.2 \mathrm{~V}$ and $-0.8 \mathrm{~V}$. Half of the adsorbed dodecylbenzensulfonate is desorbed at -0.9 . It was reversible at $-1.0 \mathrm{~V} .{ }^{19}$ The adsorption of Aerosol OT was irreversible at any potential between $-0.2 \mathrm{~V}$ and $-0.9 \mathrm{~V}$. About half of Aerosol OT adsorbed is desorbed at $-1.0 \mathrm{~V}$. Among the anionic surfactants investigated, it seems that dodecyl sodium sulfate plays different roles in the potential region between -0.4 $\mathrm{V}$ and $-0.9 \mathrm{~V}$.

Differential capacity-potential curves for cetylpyridinium chloride (cationic surfactant) at a mercury electrode in $0.05 \mathrm{M}$ $\mathrm{Na}_{2} \mathrm{SO}_{4}$ are shown in Fig. 3. Although the curves were rather complicated, which indicates different orientations of adsorbed molecules, the peaks at around $-1.5 \mathrm{~V}$ were due to adsorption-desorption of cetylpyridinium chloride. Although cetylpyridinium chloride is a cathionic surfactant, it was desorbed at any potential more negative than $-1.5 \mathrm{~V}$. 


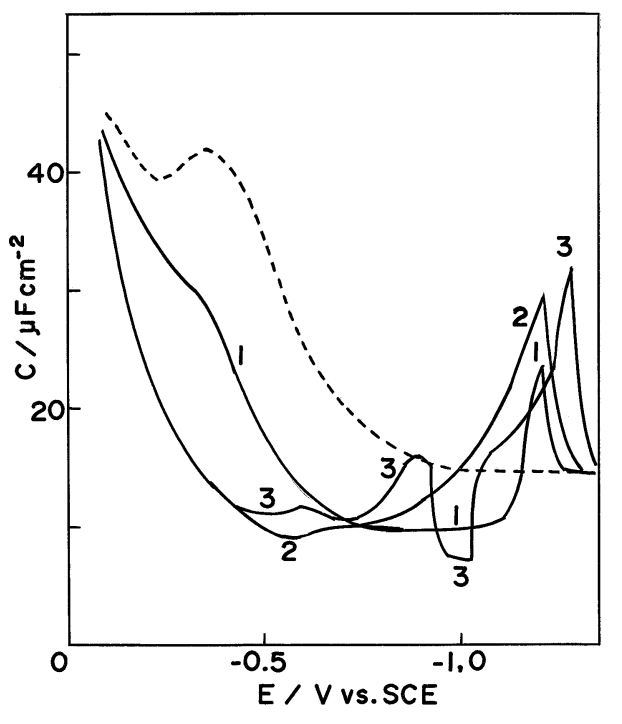

Fig. 3 Differential capacity-potential curves for cetylpyridinium chrolide at a mercury electrode in $0.05 \mathrm{M} \mathrm{Na}_{2} \mathrm{SO}_{4}$. Concentration of cetylpyridinium chrolide $(\mu \mathrm{mol} / \mathrm{L})$ : (1) 20; (2) 100; (3) 600. (----) $0.05 \mathrm{M} \mathrm{Na}_{2} \mathrm{SO}_{4}$ alone.

The effect of adsorption potential on the differential capacity-time curve for cetylpyridinium chloride is shown in Fig. 4. The adsorption of cetylpyridinium chloride at $-0.1 \mathrm{~V}$ was reversible with one adsorption region. Two adsorption regions appear at $-0.15 \mathrm{~V}$ and they were clearly observed at $-0.2 \mathrm{~V}$, as shown in Fig. 4. This indicates that two different adsorption structures exist. Irreversible adsorption with one adsorption region was observed in the potential region between $-0.4 \mathrm{~V}$ and $-0.8 \mathrm{~V}$. However, reversible adsorption was observed at $-0.85 \mathrm{~V}$. Two adsorption regions appeared at -0.9 $\mathrm{V}$. Irreversible adsorption with one adsorption region was observed at $-1.0 \mathrm{~V}$. A peak is also observed at $-1.0 \mathrm{~V}$. The peak and adsorption were maximum at $-1.2 \mathrm{~V}$. In the potential more negative than $-1.2 \mathrm{~V}$, the peak increased, while the adsorption decreased. No adsorption was observed at $-1.4 \mathrm{~V}$.

The effect of addition of cetylpyriridinium chloride on the polarographic waves was studied. ${ }^{26,27}$ However, no studies concerning the adsorption of cetylpyridinium chloride have been reported. Adsorption of cetylpyridinium bromide was studied. ${ }^{28,29}$ However, no adsorption structure was proposed. Adsorption of cetyltrimethylammonium bromide was studied by measuring differential capacitance at a dropping mercury electrode. ${ }^{30}$ They assumed a reorientation of adsorption.

Adsorption structures of cetylpyridinium chloride are considered as follows. The irreversible adsorption of cetylpyridinium chloride is due to the nitrogen atoms directly adsorbed on mercury electrode as deduced on pyridine. ${ }^{16}$ At $-0.1 \mathrm{~V}$ cetylpyridinium chloride molecules are adsorbed on the primary water layer reversibly. At $-0.2 \mathrm{~V}$ until $60 \mathrm{~s}$ they were adsorbed on the water layer; after that time, they were adsorbed directly on the electrode. At $-0.8 \mathrm{~V}$ the adsorption becomes reversible due to the repulsion of $\pi$ electrons and electrode charge. Irreversible adsorption at $-1.0 \mathrm{~V}$ corresponds a pit at $-1.0 \mathrm{~V}$ in the differential capacity-potential curves. This may due to the association of the molecules.

Differential capacity-potential curves for Hyamin 1622 (cathionic surfactant) at a mercury electrode in $0.05 \mathrm{M} \mathrm{Na}_{2} \mathrm{SO}_{4}$ are shown in Fig. 5. One adsorption potential region with one peak was observed. It is considered that the peak is due to the

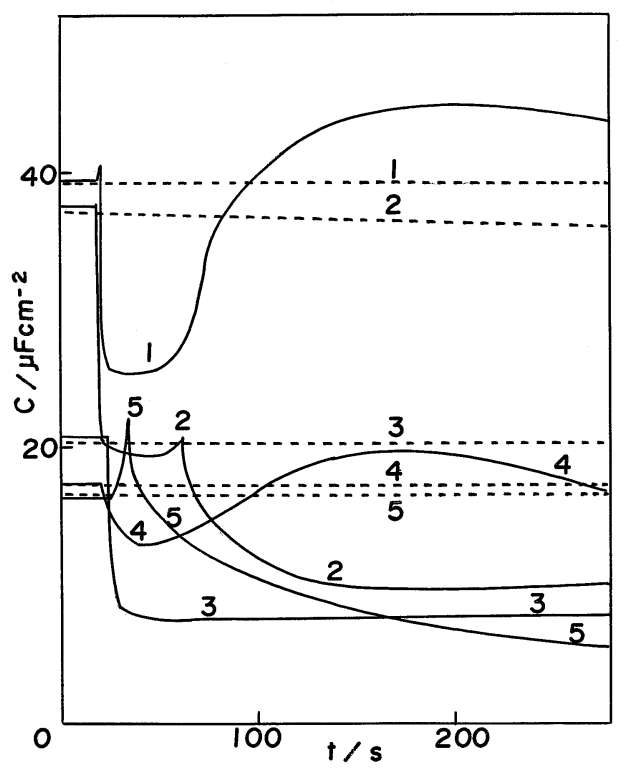

Fig. 4 Effect of adsorption potential on differential capacity-time curves for cetylpyridinium chrolide. Injected solution: $5 \mu \mathrm{L}$ of 10 $\mathrm{mM}$ cetylpyridinium chloride. Adsorption potential (V/SCE): (1) -0.1 ; (2) -0.2 ; (3) -0.6 ; (4) -0.85 ; (5) -1.0 . Dashed lines: without injection.

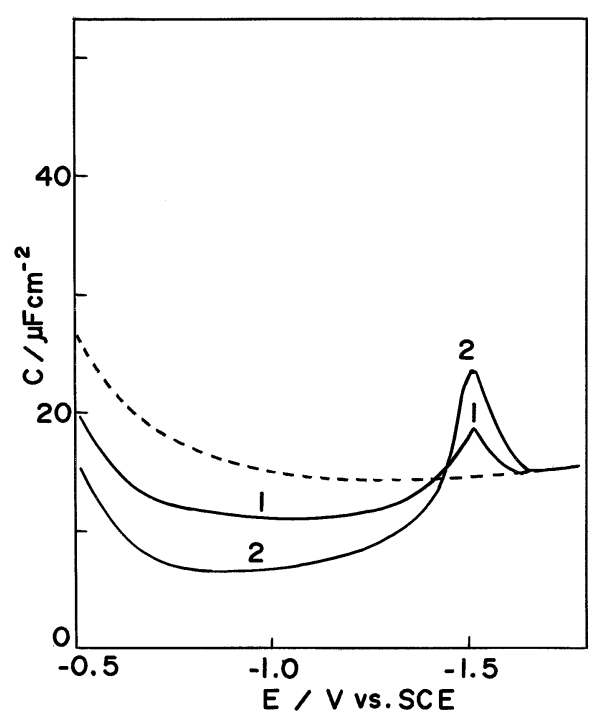

Fig. 5 Differential capacity-potential curves for Hyamin 1622 at a mercury electrode in $0.05 \mathrm{M} \mathrm{Na}_{2} \mathrm{SO}_{4}$. Concentration of Hyamin 1622 (p.p.m.): (1) 6; (2) 10. (----) $0.05 \mathrm{M} \mathrm{Na}_{2} \mathrm{SO}_{4}$ alone.

adsorption-desorption of Hyamin 1622.

The effect of adsorption potential on the differential capacity-time curve for Hyamin 1622 is shown in Fig. 6. A typical irreversible adsorption was observed at any potential investigated $(-0.2 \mathrm{~V}--1.4 \mathrm{~V})$. The maximum adsorption was observed at $-0.6 \mathrm{~V}$. It is considered that Hyamin 1622 is strongly adsorbed on a mercury electrode.

The effect of Hyamine 1622 on polarographic waves was studied. ${ }^{31}$ The reduction wave of bismuth-1,2-diaminocyclohexanetetraacetic acid complex is greatly distorted by the additon of Hyamine 1622, which means strong adsorption of Hyamine 1622.

Adsorption of Hyamine 1622 was strong and irreversible. 


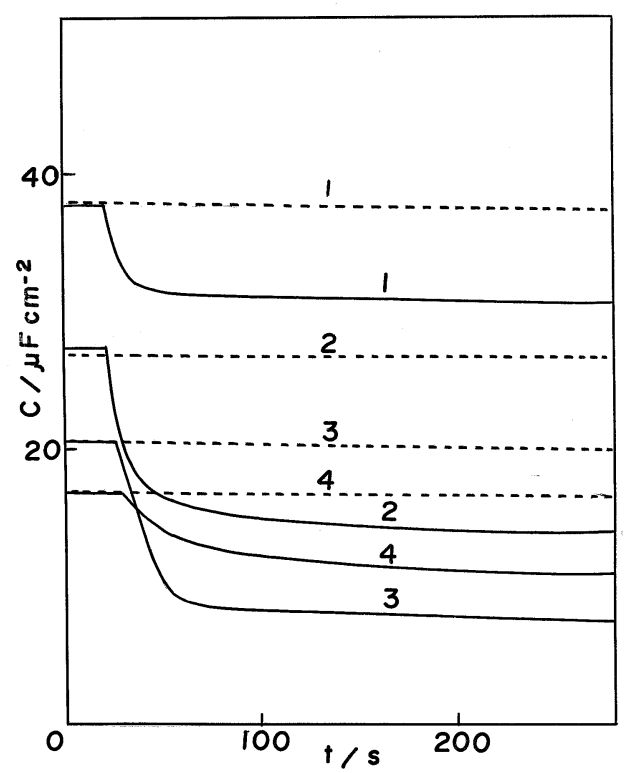

Fig. 6 Effect of adsorption potential on differential capacity-time curves for Hyamin 1622. Injected solution: $5 \mu \mathrm{L}$ of $0.01 \%$ Hyamin 1622. Adsorption potential (V/SCE): (1) -0.2 ; (2) -0.4 ; (3) -0.6 ; (4) -1.2 .

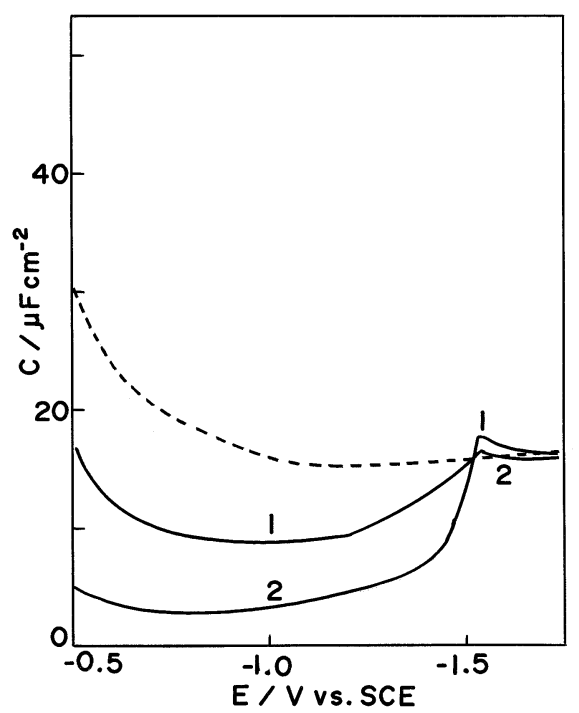

Fig. 7 Differential capacity-potential curves of tetrabutylammonium bromide at a mercury electrode in $0.05 \mathrm{M} \mathrm{Na}_{2} \mathrm{SO}_{4}$ Concentration of tetrabutylammonium bromide $(\mu \mathrm{mol} / \mathrm{L})$ : (1) 20 ; (2) 100. (---) $0.05 \mathrm{M} \mathrm{Na}_{2} \mathrm{SO}_{4}$ alone.

Compared to the adsorption of cetylpyridinium chloride, that of Hyamin 1622 was simple without changing the adsorption structure.

Differential capacity-potential curves for tetrabutylammonium bromide (cathionic surfactant) at a mercury electrode in $0.05 \mathrm{M}$ $\mathrm{Na}_{2} \mathrm{SO}_{4}$ are shown in Fig. 7. Adsorption was observed for the concentrations higher than $10 \mu \mathrm{M}$. The material was desorbed at potentials more negative than $-1.5 \mathrm{~V}$.

The effect of adsorption potential on the differential capacity-time curve for tetrabutylammonium bromide is shown in Fig. 8. Reversible adsorption was observed in the potential region between $-0.4 \mathrm{~V}$ and $-1.4 \mathrm{~V}$. At $-0.8 \mathrm{~V}$ the desorption

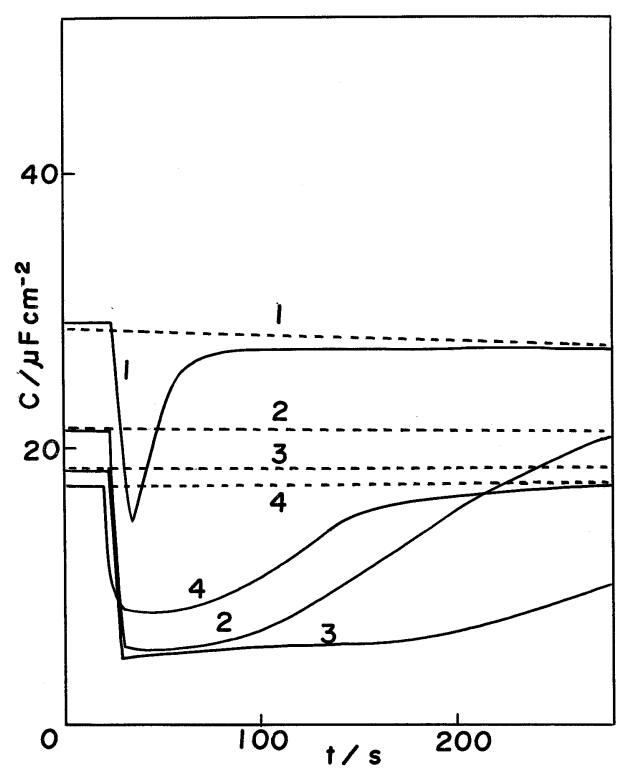

Fig. 8 Effect of adsorption potential on the differential capacity-time curves for tetrabutylammonium bromide. Injected solution: $5 \mu \mathrm{L}$ of $1 \mathrm{mM}$ tetrabutylammonium bromide. Adsorption potential (V vs. SCE): (1) -0.4; (2) -0.6; (3) -0.8; (4) -1.4. Dashed lines: without injection

speed becomes very slow. At the potential more negative than $-0.8 \mathrm{~V}$ the desorption speed became very slow.

Adsorption of tetrabutylammoium bromide and related compounds was studied..$^{32-34}$ A series of measurements of the interfacial tensions for tetrabutylammonium bromide solution led to the formation, at the surface of the electrode, both paired and non-paired ions. ${ }^{32}$ The adsorption of tetrabutylammonium bromide was reversible at all the potentials investigated. However, around $-0.8 \mathrm{~V}$ the desorption processes were very slow. This suggests a change of adsorption structure. In reversible adsorption, the adsorbed molecules lie on the primary water layer. ${ }^{14}$ In the potential region more positive than $-0.8 \mathrm{~V}$, bromide ions are specifically adsorbed. On this bromide ions layer, tetrabutylammonium cations are adsorbed. This corresponds to "paired ion" adsorption ${ }^{32}$ and anion bridge ${ }^{33}$ previously proposed. In the potential region more negative than $-0.8 \mathrm{~V}$, bromide ions are repelled from the electrode. Tetrabutylammonium cations are adsorbed on the primary water layer. This corresponds to the unpaired adsorption. ${ }^{16}$

Differential capacity-potential curves for Triton X-100 (nonionic surfactant) are shown in Fig. 9. No peak was observed in the potential investigated. Adsorption is clear in the potential region between $-0.3 \mathrm{~V}$ and $-1.3 \mathrm{~V}$.

The effect of adsorption potential on the differential capacity-time curve for Triton X-100 is shown in Fig. 10. The adsorption of Triton X-100 was irreversible at all the potentials investigated.

Adsorption of Triton $\mathrm{X}$ was studied by measuring electrocapillary curves and differential capacity potential curves and adsorption multiple layers of Triton X were assumed. ${ }^{35,36}$ The present results show irreversible strong adsorption of Triton $\mathrm{X}$. As there is no change in C-t curves, it is not certain whether multiple layers exist or not.

Differential capacity-potential curves for trioctylphosphineoxide (non-ionic surfactant) are shown in Fig. 11. Adsorption was observed with no peak.

The effect of adsorption potential on the differential 


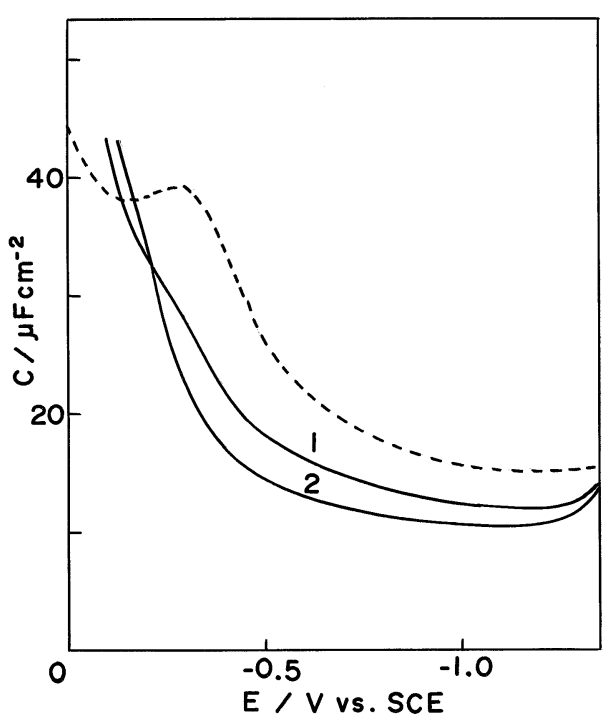

Fig. 9 Differential capacity-potential curves of Triton X-100 at a mercury electrode in $0.05 \mathrm{M} \mathrm{Na}_{2} \mathrm{SO}_{4}$. Concentration of Triton X-100 (ppm): (1) 0.06; (2) 0.1. (----) Dashed line: $0.05 \mathrm{M} \mathrm{Na}_{2} \mathrm{SO}_{4}$ alone.

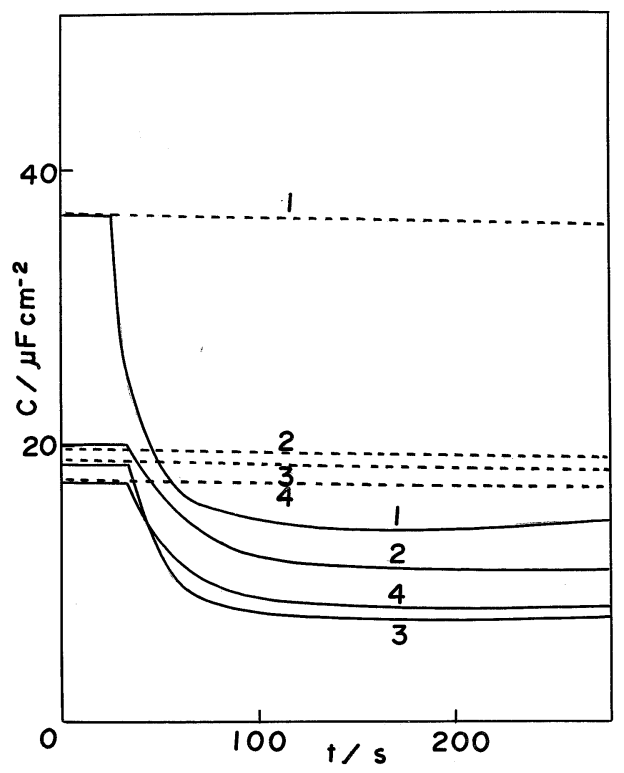

Fig. 10 Effect of adsorption potential on the differential capacity-time curves for Triton X-100. Injected solution: $1 \mu \mathrm{L}$ of saturated Triton X-100. Adsorption potential (V vs. SCE): (1) -0.2; (2) -0.6 ; (3) -1.0 ; (4) -1.4 . Dashed lines: without injection.

capacity-time curve for trioctylphosphineoxide is shown in Fig. 12. At $-0.2 \mathrm{~V}$ and $-0.3 \mathrm{~V}$, adsorption was reversible with very slow desorption. At $-0.6 \mathrm{~V}$ and $-0.9 \mathrm{~V}$ adsorption was almost irreversible.

Adsorption of trioctylphosphineoxide was studied by measuring differential capacity-time and current-time curves at a dropping mercury electrode. ${ }^{37}$ They assumed film formation. In the case of tetrabutylammonium bromide (Fig. 8), differential capacities become minimum after short times, which shows rapid adsorption. Differential capacities, however, become minimum or constant after considerable times in Fig. 12, which shows very slow adsorption.

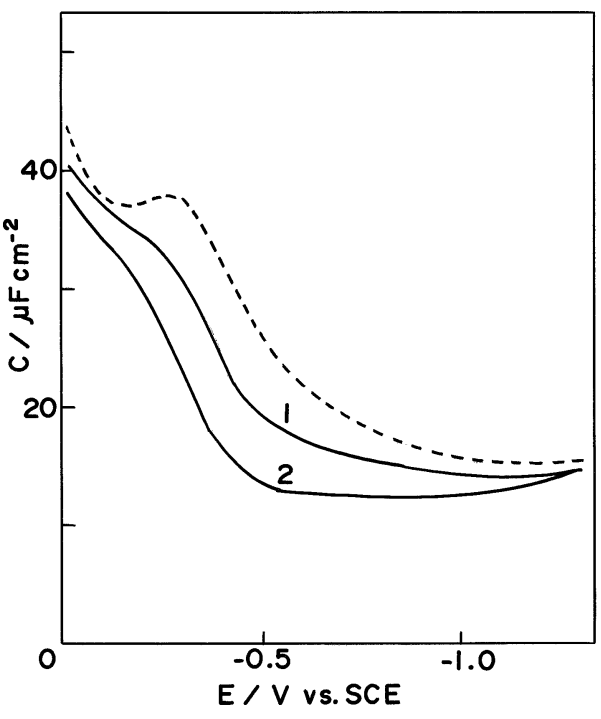

Fig. 11 Differential capacity-potential curves for trioctylphosphineoxide at a mercury electrode in $0.05 \mathrm{M} \mathrm{Na}_{2} \mathrm{SO}_{4}$. Concentration of trioctylphosphineoxide $(\%$ of the saturated solution): (1) 50; (2) 90. (----) $0.05 \mathrm{M} \mathrm{Na}_{2} \mathrm{SO}_{4}$ alone.

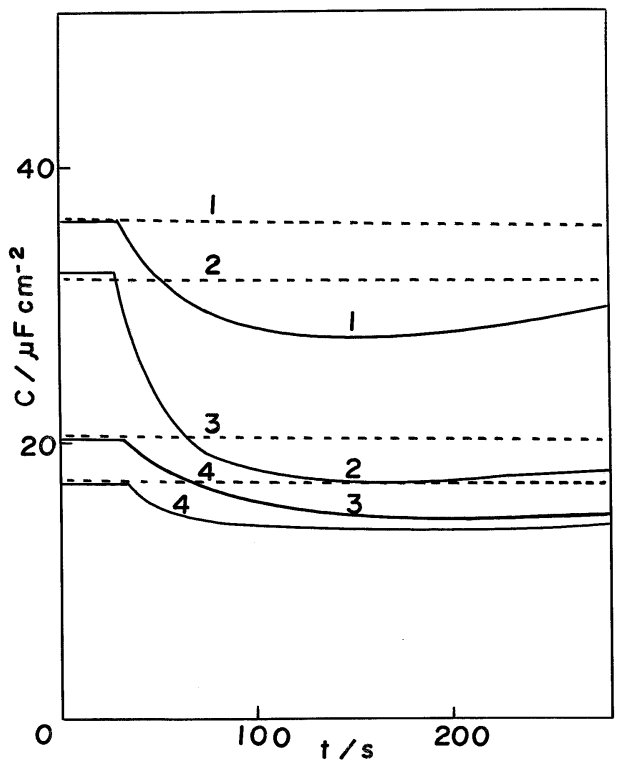

Fig. 12 Effect of adsorption potential on differential capacity-time curves for trioctylphosphineoxide. Injected solution: $20 \mu \mathrm{L}$ of saturated trioctylphosphineoxide. Adsorption potential (V vs. SCE): (1) -0.2 ; (2) -0.3 ; (3) -0.6 ; (4) -0.9 . Dashed lines: without injection.

Thus the author think that it takes very long time to build the adsorption structure. This corresponds to the film formation.

Reversibility of the surfactants can be summarized as follows. Generally, the adsorption of surfactants is irreversible. The adsorption of Hyamine 1622 and Triton X-100 is typical. Reversible adsorption is observed in restricted potential regions in the case of Aerosol OT, sodium dodecylbenzenesulfonate, cetylpiridium chloride and trioctylphosphine oxide. Adsorption of sodium dodecyl sulfate is reversible at the potential more negative than $-0.6 \mathrm{~V}$. Adsorption of tetrabutylammonium bromide is reversible at all the potentials investigated. Adsorption behavior differs among the same group of 
surfactants (e.g. anionic surfactants), which means the charges of the molecules do not play important roles in the adsorption phenomena.

\section{References}

1. I. Kobayashi, Bunseki, 1995, 2, 123.

2. M. Gerlachet, J. M. Kauffmann, G. Quarin, J. C. Vire, G. A. Bryant, and J. M. Talbot, Talanta, 1996, 43, 507.

3. A. Szymanski and Z. Lukaszewski, Anal. Chim. Acta, 1992, 260, 25.

4. B. Wyrwas, A. Szymanski, and Z. Lukaszewski, Talanta, 1995, 42, 1251.

5. N. Batina and B. Cosovic, J. Electroanal. Chem., 1987, 227, 129.

6. J.-L. Besombes, G. Mousset, and C. Mousty, J. Electroanal. Chem., 1993, 349, 127.

7. P. Nikitas and S. Sotiropoulos, J. Electroanal. Chem., 1991, 309, 1.

8. M. Rueda, A. Moto, M. L. S. Goncalues, I. Navarro, and F. Svestka, J. Electroanal. Chem., 1997, 431, 257.

9. L. Pospisil and M. Svestka, J. Electroanal. Chem., 1997, $426,47$.

10. V. Stauffer, R. Stoodley, J. O. Agak, and D. Bizzotto, J. Electroanal. Chem., 2001, 516, 73.

11. B. B. Damaskin, O. A. Baturina, E. V. Stenina, and L. N. Sviridova, Electrochim. Acta, 2001, 46, 3091.

12. H. Sawamoto and K. Gamoh, J. Electroanal. Chem., 1990, $28,421$.

13. H. Sawamoto, J. Electroanal. Chem., 1993, 361, 215.

14. H. Sawamoto, J. Electroanal. Chem., 1994, 375, 391.

15. H. Sawamoto, Nippon Kagaku Kaishi, 1996, 958.

16. H. Sawamoto, Nippon Kagaku Kaishi, 1997, 294.

17. H. Sawamoto, J. Electroanal. Chem., 1997, 432, 153.
18. H. Sawamoto, Anal. Sci., 1999, 15, 73.

19. H. Sawamoto, Nippon Kagaku Kaishi, 1998, 511.

20. S. Trasatti, Electrochim. Acta, 1992, 37, 2137.

21. G. M. Torrie and G. N. Patey, Electrochim. Acta, 1991, 36, 1677.

22. Z. Q. Tian, S. K. Sigalaev, S. Z. Zou, B. W. Mao, A. M. Funtikov, and V. E. Kazarinov, Electrochim. Acta, 1994, 39, 2195.

23. J. G. Gordon, O. R. Melroy, and M. F. Toney, Electrochim. Acta, 1995, 40, 3.

24. T. Matsui, Denki Kagaku, 1995, 63, 275.

25. E. Spohr, G. Toth, and K. Heinzinger, Electrochim. Acta, 1996, 41, 2131.

26. M. C. Dubey and M. Singh, Indian J. Chem., Sect. A, 1979, 18A, 2, 174; CA 92:66751b.

27. A. Varshney, M. Krishna, S. K. Jha, and M. Singh, J. Indian Chem. Soc., 1980, 57, 816; CA 93:17991w.

28. S. L. Gupta and S. K. Sharma, Electrochim. Acta, 1965, 10, 151.

29. S. K. Sharma, Electrochim. Acta, 1971, 16, 517.

30. M. K. Kaisheva and V. K. Kaishev, God. Sofii. Univ., Khim. Fak, 1979, 70, Pt.2, 71; CA 93:56860t.

31. N. Gundersen and E. Jacobsen, J. Electroanal. Chem., 1969, 20, 13 .

32. M. Hamdi, R. Bennes, D. Schuhmann, and P. Vanel, J. Electroanal. Chem., 1980, 108, 255.

33. M. A. V. Devanathan and M. J. Fernando, Trans. Faraday Soc., 1962, 58, 368.

34. L. Nemec, Collection Czechoslov. Chem. Commun., 1966, 31,1162

35. T. Ohsaka, H. Kato, and T. Yoshida, Denki Kagaku, 1973, $41,156$.

36. T. Ohsaka, H. Yamamoto, and T. Yoshida, Bull. Chem. Soc. Jpn., 1973, 46, 1320.

37. H.-D. Dorfler and E. Muller, J. Electroanal. Chem., 1979, 105, 383 . 